\title{
UPACARA SIPAHA SADA PADA AGAMA PARMALIM DI MASYARAKAT BATAK TOBA DALAM KAJIAN SEMIOTIKA \\ Oleh: \\ Wiflihani* \\ Agung Suharyanto**
}

\begin{abstract}
Abstrak
Bunyi gondang hasapi mengalun dari dalam parsantian (rumah ibadah) mengiringi Ihutan (pemimpin agama) yang berdiri paling depan diantara kepulan dupa dari sanganonna, sambil manortor (menari) yang diikuti semua pengikutnya yang manatea (menari sambil duduk bersila). Asap (dupa) yang berasal dari sanganon (sebagai simbol alat pemanasnya) dan perasan jeruk purut sebagai pangurason untuk air pemandiannya, kain putih (hio putih) sebagai kain pembalutnya (abit sabinna) serta kain panjang tenun (ulos jugia na so pipot) sebagai kain gendongannya. Dalam upacara ini, Simarimbulubosi dipercayai berkenan menerima "sembah" dari orang yang percaya kepadanya dengan bentuk "sembah"nya adalah persembahan bermacam pelean (sesaji). Persembahan pelean (sesaji) tersebut terdiri dari kambing putih dan ayam "berwarna hitam bercampur putih" (jarumbosi) dan sesaji lainnya sebagai kurban untuk menyambut hari kelahirannya.
\end{abstract}

Kata Kunci: Upacara Sipaha Sada, Agama Parmalim, Batak Toba, Semiotika

\section{A. Parmalim dan Upacara Sipaha Sada}

Masuknya pengaruh asing dan penyebaran agama (Kristen dan Islam) ke tanah Batak, khususnya Batak Toba, mengakibatkan keberlangsungan kepercayaan Batak yang dipimpin oleh para parbaringin (iman-imam tradisional yang memimpin upacara-upacara bius selaku pembantu utama Sisingamangaraja di tiap bius, mengalami gangguan. Untuk mengatasi hal tersebut pada tahun 1870 Sisingamangaraja XII memutuskan untuk memimpin langsung kepercayaan tersebut, yaitu Ugamo Malim.

Malim adalah sebuah agama yang lahir di Tanah Batak yang hingga kini masih tetap eksis sebagai sebuah anutan kepercayaan sebahagian masyarakat etnis Batak Toba. Agama ini diresmikan oleh salah seorang murid sekaligus sahabat Sisingamangaraja XII yang bernama Raja Mulia Naipospos ketika gencar-gencarnya misionaris Kristen Barat memasuki Tanah Batak.

Ugamo Malim berasal dari kata ugamo dan malim. Ugamo adalah segala sesuatu yang berhubungan dengan ngolu partondion (alam spritual), yaitu tata cara hubungan manusia dengan alam roh, sedangkan malim artinya suci. Dengan demikian, Ugamo Malim adalah pengatur segala sesuatu yang berhubungan dengan ngolu partondion (alam spritual), yang dilaksanakan berdasarkan prinsip-prinsip kesucian yang

\footnotetext{
*Dosen Jurusan Sendratasik, Program Studi Seni Musik, FBS - UNIMED

${ }^{* *}$ Dosen Program Studi Pendidikan Antropologi, FIS - UNIMED
} 
bersumber dari Debata Mula Jadi Na Bolon (pencipta). Adapun penganut kepercayaan ini disebut Parmalim, yaitu kumpulan orang-orang yang menjalankan Ugamo Malim.

Pada saat ini, Ugamo Malim selain diartikan sebagai aliran kepercayaan kepada Tuhan Yang Maha Esa juga sebagai wadah atau tempat untuk menjalankan prinsip-prinsip hamalimon (kesucian) yang bersendikan kepada Si Sia-Sia Ni Habatahon yang terdiri dari: MarDebata (mempunyai Tuhan Yang Maha Esa), Mar-Adat (mempunyai adat kebiasaan yang berisi nilai-nilai luhur), Mar-Patik (mempunyai kitab penuntun kehidupan yang disebut Pustaha Habonaron yang berfungsi sebagai pengatur tata laku manusia dalam berhubungan dengan Tuhan, alam, dan sesama), Mar-Uhum (memiliki hukum kebenaran penegak keadilan dan kesucian hidup), serta Mar-Harajaon, yaitu sebagai implementasi kepatuhan umat Parmalim terhadap raja atau pemimpinnya.

Dalam praktik peribadatannya, Ugamo Malim percaya kepada Mula Jadi Na Bolon sebagai pencipta segala sesuatu yang ada, Tuhan Yang Maha Esa. Dengan demikian, kehidupan dan kematian adalah atas kuasanya. Akibat keesaan Mula Jadi Na Bolon ini maka umat Parmalim selalu mengadakan hubungan dengannya, memohon kebahagiaan hidup jasmaniah di dunia (ngolu pardagingon), serta kehidupan rohaniah dan spiritual (ngolu partondion) di akhirat (habangsa panjadian) nantinya.

Agama Malim memiliki sejumlah upacara ritual yakni upacara mararisabtu (upacara yang dilaksanakan setiap hari Sabtu), martutuaek (upacara kelahiran anak), pasahat tondi (upacara kematian), mardebata (upacara sembah debata), mangan na paet (upacara memakan yang pahit), sipaha sada (upacara kelahiran Simarimbulubosi), sipaha lima (upacara persembahan sesaji besar), mamasu-masu (upacara memberkati perkawinan) dan manganggir (upacara pensucian diri). Semua upacara ini masih tetap diamalkan oleh penganut agama Malim hingga kini. Tiga dari sembilan bentuk upacara ritual tersebut, yakni; mardebata, sipaha sada dan sipaha lima - semuanya menggunakan musik tradisional (gondang) dan diiringi dengan tari-tarian (tortor) pada saat ritus demi ritus dilangsungkan. Artinya, baik gondang maupun tortor merupakan bagian integral dalam ketiga jenis upacara itu. Keduanya wajib dilaksanakan jika ingin upacara peribadatan itu mendapatkan nilai yang paripurna.

Upacara Sipaha Sada adalah upacara yang dilaksanakan setiap awal tahun pada bulan pertama (Sipaha Sada) menurut kalender Batak (Parhalaan). Tujuan dilaksanakannya upacara ini adalah sebagai ucapan syukur atas kelahiran Tuhan Simarimbulu Bosi ke tengah-tengah umat Parmalim untuk menebus segala dosa dan kesalahan sehingga mereka disucikan, dan pada saatnya nanti akan memperoleh kehidupan yang kekal (ngolu partondion) di tempat yang mahasuci (habangsa panjadian) di banua ginjang (benua atas). Sedangkan makna dari upacara ini adalah pertanda kemenangan iman umat Parmalim dalam melawan kuasa iblis (sibolis) kegelapan. 
Dalam pelaksanaan upacara Sipaha Sada, untuk berkomunikasi memohon berkat dari Debata Mula Jadi Na Bolon dan penguasa alam roh lainnya, disampaikan melalui tonggo-tonggo (doa ritus) oleh Ihutan $^{l}$ sebagai imam pemimpin upacara. Selain itu juga dalam setiap pelaksanaannya, dihadirkan daupa, air pangurason, hio putih dan ulos jugia na so pipot. Dan yang tidak boleh ketinggalan adalah pelean (sesaji) yang terdiri dari kambing putih dan ayam "berwarna hitam bercampur putih" (jarumbosi) dan sesaji lainnya sebagai kurban untuk menyambut hari kelahirannya. Namun dalam pelaksanaannya, praktek mamele (bersaji) dan martonggo (berdoa) di atas belumlah sempurna tanpa kehadiran parhinaloan atau Gondang Hasapi. ${ }^{2}$ Seluruh rangkaian permohonan melalui tonggo-tonggo dan pelean (sesajian) baru memperoleh kesempurnaan apabila gondang hasapi dipakai untuk mansahaphon (mengesahkan) dan megantarkan permohonan tersebut ke tujuannya masing-masing. dan yang paling menarik adalah disajikannya gondang khusus untuk memperingati hari kelahiran Simarimbulubosi yang disebut dengan gondang pangharoanan (gendang menyambut kelahiran) dalam upacara Sipaha Sada ini.

Ada sekitar 12 macam gondang khusus untuk memperingati hari kelahiran Simarimbulubosi. Berikut adalah nama-nama gendang yang dimaksud:

(1) Gondang untuk ibu yang melahirkan Simarimbulubosi

(2) Gondang Hatutubu (gendang saat kelahiran)

(3) Gondang Pangharoanan (gendang menyambut kelahirannya)

(4) Gondang Didang-Didang-nya (gendang membuai-buainya)

(5) Gondang Haposoon-nya (gendang waktu mudanya)

(6) Gondang Ulaon-nya (gendang "kenabiannya")

(7) Gondang Habengeton (gendang ketabahan)

(8) Gondang Panghonghopan-nya (gendang pembelaannya)

(9) Gondang Hasiakbagion-nya (gendang penderitannya)

(10) Gondang Hamonangan-nya (gendang kemenangannya)

(11) Gondang Parolop-Olopan-nya (gendang merayakan kegembirannya)

(12) Gondang Hasahatan (gendang tempat yang dituju, penerima dan perantara)

Semua nama gendang yang dikemukakan di atas, wajib dipersembahkan pada setiap upacara Sipaha Sada. Bunyi masing-masing gendang itu sudah baku dan tidak boleh ditukar-tukar sampai kapan pun. Setiap gendang ini dibunyikan, maka harus disertai dengan tortor (tari), tapi yang boleh menari adalah Ihutan sendiri di depan persembahan,

\footnotetext{
${ }^{1}$ Arti Ihutan dalam bahasa Batak adalah yang diikuti, ikutan atau atau anutan. Namun dimaknai juga sebagai pemimpin tertinggi dalam konteks organisasi agama Malim.

${ }^{2}$ (4 Gondang hasapi ialah ensambel musik Batak Toba yang terdiri dari: hasapi anak dan hasapi Ma (fretless short necked lute two strings), 1 buah garantung (xylofon) yang terdiri dari lima bilah kayu bernada, 1 buah sarune etek (oboe), dan 1 buah hesek (concassion idiophone).
} 
sementara peserta lainnya hanya boleh mangatea (bersembah dengan sepuluh jari) dengan posisi tetap duduk.

Ihutan-lah yang bertindak sebagai pejabat (manghasuhutkon) dalam mempersembahkan sesaji sembahan itu. Peranan ihutan di sini adalah sebagai wakil dari Raja Nasiakbagi yang pertama sekali mengisbatkan (menetapkan) upacara Sipaha Sada wajib diamalkan. Hal ini juga bermakna bahwa Ihutan-lah yang bertindak sebagai wakil seluruh warga parmalim dalam mempersembahkan sesaji sembahan itu.

Demikian sekilas acara ritual Ugamo Malim dalam upacara Sipaha Sada untuk memperingati kelahiran Simarimbulubosi yang pelaksanaannya jatuh pada hari kedua dan ketiga setiap bulan kesatu menurut parhalaan (kalender) Batak di Hutatinggi Laguboti Toba Samosir Sumatera Utara. Upacara ini diikuti oleh kurang lebih 1.000 orang etnis batak toba yang terdiri dari berbagai punguan (kumpulan) yang tersebar di sebagian besar wilayah provinsi Sumatera Utara.

\section{B. Sipaha Sada dalam Kajian Semiotika Pierce}

Melihat sekilas upacara Sipaha Sada, tidak menutup adanya kenyataan bahwa banyak tanda yang dimulai dari Gondang hasapi sebagai alat musik pengiring upacara beserta pargonsi (pemain musik)nya sampai tortor (tarian) yang dilakukan oleh Ihutan (pemimpin agama) dalam rangkaian upacara. Tidak hanya dari pelean (persembahan) dan alat-alat upacara yang digunakan, bahkan sampai peserta upacara yang berkumpul mendoakan dan melakukan persembahan kepada, Simarimbulubosi sebagai sosok yang dipercaya membawa kebenaran. Dari Sipaha sada (bulan satu) sebagai waktu untuk menyelenggarakan upacara sampai kepada parsantian (rumah ibadah) sebagai tempat penyelenggaraannya. Tanda-tanda inilah yang mencoba untuk dikupas sebagai bagian dari fenomena yang muncul pada sebuah acara budaya dalam satu masyarakat.

Memang sangat menarik apabila membicarakan ilmu tentang tanda-tanda untuk melihat sebuah peristiwa budaya. Charles Sanders Pierce mengatakan bahwa tanda adalah sesuatu yang dapat mewakili sesuatu yang lain dalam batas-batas tertentu, selain itu juga mengacu kepada sesuatu yang disebut dengan objek yang "mewakili" atau "menggantikan" (Hoed, 2008: 4). Dengan mendengar suara musik dari gondang hasapi yang mengalun lembut adalah sebuah tanda bagi berlangsungnya upacara Sipaha Sada yang dilakukan oleh komunitas warga Parmalim di Huta Tinggi Laguboti. Alunan gondang hasapi yang terdengar tersebut hanya setahun sekali dibunyikan pada saat upacara Sipaha Sada untuk merayakan kelahiran Tuhan Simarimbulubosi. Dari rangkaian panjang alunan gondang yang mengalir, terdapat satu gondang khusus yang menceritakan kelahiran Simarimbulubosi yang mitosnya sangat mereka percayai. Itulah dasar dialunkannya gondang hasapi oleh pargonsi (pemusik) seperti yang diyakini oleh komunitas warga Parmalim, sehingga tanda tersebut bekerja dengan sendirinya. 
Peirce mengatakan bahwa tanda-tanda berfungsi sebagai mediator antara dunia eksternal dan dunia internal ide. Tanda adalah representasi mental dari objek, dan objek dapat dikenali dari persepsi tandanya. Peirce mendefinisikan 'semiosis' sebagai proses representasi fungsi objek sebagai tanda (sign) (Hoed, 2008: 18). Model Peirce tentang unsur makna tersebut dapat digambarkan sebagaimana pada Gambar berikut:

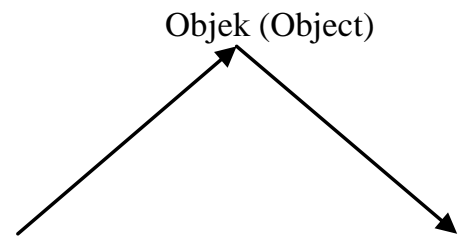

Tanda (representamen) Interpretan (interpretant)

Gambar proses semiosis dari Peirce (Hoed 2001: 199)

“Sebuah 'tanda' (sign) atau 'representamen' (representamen) mengacu pada sesuatu di luar dirinya sendiri yaitu 'objek' (object), yang dipahami oleh seseorang: objek memiliki efek bagi 'interpretan' (interpretant)" (Nöth,1990:42). Sehingga dengan demikian, "Proses pemaknaan representamen, objek, dan interpretan yang disebut semiosis itu terjadi dengan sangat cepat dalam pikiran manusia" (Hoed,2001:118). "Proses semiosis adalah proses di mana suatu tanda berfungsi sebagai tanda, yakni representamennya mewakili yang diwakilinya. Peirce (dikutip Nöth, 1990:42) mengemukakan semiosis merupakan hubungan segi tiga antara sign (tanda), thing signified (petanda), dan cognition produced in the mind (kognisi yang dihasilkan dalam persepsi). Karena yang diindera sebenarnya adalah representamen, maka seringkali representamen disebut tanda: “. . . Nothing is a sign unless it is interpreted as a sign". Tidak satu pun dapat disebut sebagai tanda, kecuali tanda itu diinterpetasikan sebagai tanda “.... Peirce melihat semiosis tersebut sebagai suatu proses yang secara teoretis berlanjut tanpa akhir karena manusia akan terus berpikir" (Hoed 2008: 18).

\section{Gondang Hasapi}

Melihat sekilas upacara sipaha sada, tidak menutup adanya kenyataan bahwa banyak tanda yang dimulai dari Gondang hasapi sebagai alat musik pengiring upacara beserta pargonsi (pemain musik)nya sampai tortor (tarian) yang dilakukan oleh Ihutan (pemimpin agama) dalam rangkaian upacara. Mulai dari pelean (persembahan) dan alat-alat upacara yang digunakan sampai peserta upacara yang berkumpul mendoakan dan melakukan persembahan kepada, Simarimbulubosi sebagai sosok yang dipercaya membawa kebenaran. Dari Sipaha Sada (bulan satu) sebagai waktu untuk menyelenggarakan upacara sampai kepada parsantian (rumah ibadah) sebagai tempat penyelenggaraannya. Tanda-tanda inilah yang mencoba untuk dikupas sebagai bagian dari 
fenomena yang muncul pada sebuah acara budaya dalam satu masyarakat.

Gondang Hasapi adalah sebuah tanda (representamen) yang ketika dimainkan oleh Pargonsi (pemusik) dalam upacara Sipaha Sada terdapat 12 gondang yang berbeda nama dan bunyinya (objek) yang menghasilkan interpretasi bagi warga Parmalim yaitu:

(1) Gondang untuk ibu yang melahirkan Simarimbulubosi yang bertujuan untuk menghormati ibunda Simarimbulubosi atas jasa dan pengorbanannya. Melalui dirinyalah lahir seseorang yang membawa kebaikan kepada umat manusia,

(2) Gondang Hatutubu (gendang saat kelahiran), yang bermakna untuk mengenang dan memperingati saat-saat kelahiran Simarimbulubosi,

(3) Gondang Pangharoanan (gendang menyambut kelahirannya), untuk mengenang dan memperingati saat-saat masyarakat pada masa itu menyambut kelahiran Simarumbulubosi,

(4) Gondang Didang-Didang-nya (gendang membuai-buainya), yang bermakna mengenang dan memperingati saat-saat "boru ni debata" (putri Debata) membuai-buai Simarumbulubosi setelah lahir dari rahim ibunya,

(5) Gondang Haposoon-nya (gendang waktu mudanya), yaitu mengenang dan memperingati waktu Simarumbulubosi masih kecil dan muda belia,

(6) Gondang Ulaon-nya (gendang "kenabiannya"), yaitu mengenang dan memperingati saat Simarumbulubosi menjalankan togas menyampaikan ajaran kepada umatnya,

(7) Gondang Habengeton (gendang ketabahan), yaitu mengenang dan memperingati ketabahan hatinya dalam memimpin dan mengayomi umatnya selama ia berada di dunia ini (Banua Tonga),

(8) Gondang Panghonghopan-nya (gendang pembelaannya), yaitu mengenang dan memperingati pembelaannya terhadap umatnya,

(9) Gondang Hasiakbagion-nya (gendang penderitannya), yaitu mengenang dan memperingati tentang penderitaannya selama memimpin dan mengayomi umatnya,

(10) Gondang Hamonangan-nya (gendang kemenangannya) yaitu mengenang dan memperingati kemenangannya ketika berhadapan dengan iblis,

(11) Gondang Parolop-Olopan-nya (gendang merayakan kegembirannya) yaitu mengenang dan memperingati saat-saat kegembiraannya setelah menang melawan iblis,

(12) Gondang Hasahatan (gendang tempat yang dituju, penerima dan perantara), yang bermakna sebagai pernyataan bahwa Simarumbulubosi adalah sebagai perantara, penerima atau penghubung antara manusia dengan Debata, terutama dalam hal doa dan segala amal ibadat selama manusia berada di dunia ini. 
Membunyikan gondang dalam upacara Sipaha Sada bukanlah hanya sekedar pelengkap yang hanya bertujuan untuk menghiasi jalannya upacara, melainkan mempunyai makna yang tersendiri dalam keseluruhan prosesi upacara. Jika dimaknakan, gondang itu berfungsi sebagai perantara sekaligus sebagai alat untuk berkomunikasi kepada supernatural guna menyuarakan hati seseorang selama upacara itu berlangsung. Artinya, melalui gondang itulah niat dan hajat para peserta upacara tersampaikan kepada Debata Mulajadi Nabolon. Jika seorang peserta misalnya tidak mampu untuk menyuarakan hatinya lewat doadoa, maka melalui iringan suara gondang itulah suara hatinya tersampaikan.

Biasanya gendang itu dibunyikan pada setiap kali pimpinan agama atau pimpinan upacara (religious spesialist) telah selesai melafalkan sebuah doa-doa (tonggo-tonggo) atau dengan kata lain disela-sela pembacaan antara doa yang satu dengan doa yang berikutnya. Bunyibunyian gondang dalam konteks ini dapat juga dimaknakan sebagai kenderaan untuk merayu dan membujuk sang supernatural agar semua permohonan itu dapat dikabulkan. Berbarengan dengan bunyi-bunyian gondang itu semua peserta tentu harus menari seraya berpasrah diri dan bersikap rendah hati. Itu berarti bahwa sebuah bunyi-bunyian gondang merupakan rangkaian dari sebuah doa-doa yang dilafalkan.

Pargonsi (tukang gendang) berasal dari kata gonsi sama artinya dengan gondang, sedang orang yang membunyikan peralatan gendang disebut pargonsi (tukang gendang). Pargonsi (tukang gendang) tidaklah hanya sekedar seniman di mata warga parmalim (penganut agama Malim). Bagi agama Malim, pargonsi sangat berperanan penting dalam setiap upacara ritual, terutama upacara yang menggunakan peralatan gendang. Dalam ajaran agama Malim ada satu kepercayaan yang mengisyaratkan bahwa seluruh anggota pargonsi mempunyai derajat yang lebih tinggi jika dibandingkan dengan anggota biasa parmalim meskipun tidak boleh disejajarkan sama dengan Ihutan. Mengingat derajatnya yang demikian itu mengakibatkan keharusan bagi setiap anggota parmalim untuk menghormatinya dan memperlakukannya dengan baik. Tidak boleh memperlakukannya dengan cara tidak senonoh dan "anggap enteng" baik pada saat upacara berlangsung maupun di luar upacara. Menurut kepercayaan, fungsi pargonsi dalam upacara ritual bukanlah hanya sekedar memukul gondang yang menghasilkan bunyibunyian yang merdu, melainkan memiliki makna lebih dari itu, yakni menyampaikan alu-alu (pengaduan) dan manurirang (menyuarakan) apa yang ada dalam hati peserta. Pargonsi-lah yang menghantarkan dan menyampaikan niat dan permohonan yang ada dalam hati para peserta upacara. Itulah sebabnya dalam setiap hendak mempersembahan gondang harus lebih dahulu memohon kepada pargonsi nama gondang yang akan dipersembahkannya itu. Tak terkecuali Ihutan sendiri harus lebih dulu memohon kepada pargonsi setiap kali hendak mempersembahkan sesuatu bunyi-bunyian gendang. 
Pargonsi ini sering juga dijuluki dengan nama "Bataraguru humundul", karena menurut kepercayaan Malim bahwa ilmu dan keterampilan pargonsi dalam membunyikan gendang itu bukanlah semata-mata kerana mereka berguru atau mereka pelajari dari seseorang yang ahli melainkan lebih karena datangnya tetesan ilmu dari sahala pangajari (roh pengajar) hinggap pada diri mereka. Roh pengajar itu dipercayai bersumber dari Bataraguru ${ }^{3}$.

\section{Tor-tor dan Pelean}

Tor-tor dalam upacara Sipaha Sada adalah sebuah tanda dalam rangkaiannya oleh komunitas Parmalim, yang dilakukan oleh Ihutan yang manortor di depan sesaji dan umatnya pada setiap gondang yang dibunyikan, sementara peserta lainnya hanya boleh mangatea (bersembah dengan sepuluh jari) dengan posisi tetap duduk. Sehingga interpretannya adalah Ihutan-lah yang bertindak sebagai pejabat (manghasuhutkon) dalam mempersembahkan sesaji sembahan pada upacara sipaha sada. Peranan Ihutan adalah sebagai wakil dari Raja Nasiakbagi yang pertama sekali menetapkan upacara Sipaha Sada. Dengan kata lain bahwa adalah Ihutan-lah yang bertindak sebagai wakil seluruh warga parmalim dalam mempersembahkan sesaji sembahan itu.

Arti tortor dalam bahasa Batak adalah "tarian", akan tetapi bentuk tarian yang dimaksudkan di sini adalah tarian khas orang Batak Toba. Dalam agama Malim, tortor adalah salah satu komponen dalam upaca ritual yang menggunakan peralatan gendang. Tortor itu sendiri dalam upacara ritual sama dengan gendang yang berfungsi sebagai perantara untuk menyampaikan niat dan suara hati masing-masing peserta kepada Debata Mulajadi Nabolon. Dari gerak tortor itu akan tergambar bagaimana keadaan atau suasana hati seseorang dalam mengabdikan diri kepadaNya. Jika keadaan jiwanya penuh dengan arsak (kesusahan hati), jelas akan tampak dalam lakon tortor itu kurang bergairah. Itu bermakna bahwa kekuatan batin dan ketulusan hatinya dalam mengikuti upacara itu kurang mantap dan kurang khusuk. Berbeda dengan orang yang tampak gerak tortor-nya sangat bergairah dan menunjukkan sikap kegembiraan, itu bermakna bahawa orang bersangkutan telah mempersiapkan diri dari segi fisik maupun mental termasuk kesiapan rohani seperti kesabaran dan keikhlasan.

Pelean (persembahan) dan alat-alat upacara yang digunakan adalah sebuah tanda dari objeknya yaitu seperti kambing putih dan ayam "berwarna hitam bercampur putih" (jarumbosi) dan sesaji lainnya sebagai kurban untuk menyambut hari kelahirannya beserta peralatan dupa dalam setiap upacara agama sama fungsinya dengan pelean adalah dupa, air pangurason, hio putih dan ulos jugia na so pipot. Sehingga interpretannya adalah pardaupaan sebagai simbol untuk mengingatkan pada masa kelahirannya di mana ibundanya membuat satu "perapian"

\footnotetext{
${ }^{3}$ Bataraguru adalah salah satu Tuhan atau Dewa dari Debata Natolu (Debata yang tiga)
} 
yang disebut dengan sanganon (api pemanas suhu untuk orang yang sedang bersalin). Peralatan ini berfungsi agar di sekitar Simarimbulubosi tercipta suhu udara yang tidak terlalu dingin. Sedangkan dalam pembuatan pangurason yang biasanya anggir (jeruk purut) hanya dibelah, tetapi kali ini harus diperas dan disaring agar kebersihannya dapat lebih terjamin. Fungsi pangurason ini adalah sebagai alat untuk memandikan dan mensucikannya. Kain putih (hio putih) sebagai pembalutnya (abit sabinna), ulos jugia na so pipot adalah sebagai kain penggendongnya. Semua peralatan yang disediakan pada upacara sipaha sada itu dijadikan sebagai simbol mengingatkan saat-saat kelahirannya pada masa dahulu. Mengenai sesaji kambing putih dan ayam berwarna adalah sebagai penghormatan (somba) dari orang-orang yang mempercayainya. Dan terakhir adalah upacara sipaha sada pada komunitas Parmalim adalah sebuah tanda bagi rangkaian upacara yang memakai gondang hasapi, tortor, tonggo-tonggo dan pelean sebagai objek dari interpretannya tentang ketaatan mereka dalam menjalankan kepercayaan kepada Mula Jadi Na Bolon dan Simarimbulubosi.

Manusia tidak lepas dari lingkungan sosial budayanya dalam memberi makna kepada tanda. Jadi, semiotik adalah melihat kebudayaan sebagai sistem tanda yang oleh anggota masyarakatnya diberi makna sesuai dengan konvensi yang berlaku dalam proses semiosis memberikan "makna" unsur kebudayaan yang dipandang sebagai tanda. Dengan demikian, akan diperoleh "pengetahuan" dan "pemahaman" atas gejala kebudayaan yang diamati. Pada Peirce semiotik lebih diarahkan pada pemahaman tentang bagaimana kognisi kita memahami apa yang berada di sekitar kita, baik lingkungan sosial, alam, maupun jagat raya.

\section{Daftar Pustaka}

Gultom, Ibrahim. 2010. Agama Malim di Tanah Batak. Jakarta: Bumi Aksara.

Hoed, Benny H. 2001. Dari Logika Tuyul ke Erotisme. Magelang: Indonesia Tera. . 2008. Semiotik dan Dinamika Sosial Budaya.Jakarta: FIB UI Depok

Hutasoit, M. 1976. Gondang Dohot Tortor Batak. Tarutung.

Ihromi, T.O. 1981. Pokok-Pokok Antropologi Budaya. Jakarta:PT. Gramedia.

Marbun, M.A., dan I.M.T. Hutapea. 1987. Kamus Budaya Batak. Jakarta: Balai Pustaka.

Merriam, Alan P. 1964. The Anthropology of Music. Evaston Ill: North Western University Press.

Naiborhu, Torang. 2006. Gondang Hasapi: Fungsinya pada Upacara Ritual Parmalim Sipaha Sada, dalam Etnomusikologi, Vol.1 No. 3, Januari 2006: 299-309

Nöth, Winfried. 1999. "Pierce", dalam Handbook of Semiotics. Bloomington: Indiana University Press. 
Sidjabat, W.B. 1983. Ahu Sisingamangaraja. Jakarta: Sinar Harapan.

Situmorang, Sitor. 1993. Guru Somalaing dan Modigliani Utusan Raja Rom. Jakarta: Grafindo Mukti.

Suradi, HP. Pengkajian Nilai-nilai Luhur Budaya Spritual Bangsa Propinsi Sumatera Utara. Jakarta: Departemen Pendidikan dan Kebudayaan, 1992/1993.

Tambunan, E.H. 1982. Sekelumit mengenai masyarakat Batak Toba dan Kebudayaannya. Bandung: Tarsito.

Tampubolon, C.B. 1985. Ulos Batak. Jakarta: BPK Gunung Mulia.

Vergowen, J.C. 1986. Masyarakat dan Hukum Adat Batak Toba. Jakarta: Pustaka Azet. 